\title{
Determinants of Adrenal Androgen Hypofunction in Premenopausal Females With Rheumatoid Arthritis
}

\author{
R. IMRICH ${ }^{1,2}$, M. VLCEK ${ }^{1,2}$, J. KERLIK ${ }^{1}$, M. VOGESER $^{3}$, F. KIRCHHOFF $^{3}$, \\ A. PENESOVA ${ }^{1}$, Z. RADIKOVA ${ }^{1}$, J. LUKAC ${ }^{4}$, J. ROVENSKY $^{4}$
}

${ }^{1}$ Laboratory of Human Endocrinology, Institute of Experimental Endocrinology, Slovak Academy of Sciences, Bratislava, Slovakia, ${ }^{2}$ Center for Molecular Medicine, Slovak Academy of Sciences, Bratislava, Slovakia, ${ }^{3}$ Institute of Clinical Chemistry, Hospital of the University of Munich, Munich, Germany, ${ }^{4}$ National Institute of Rheumatic Diseases, Piestany, Slovakia

Received September 19, 2013

Accepted November 21, 2013

On-line February 24, 2014

\section{Summary}

The aim of our study was to investigate adrenocortical function in the context of disease activity and inflammatory status in premenopausal RA females. Adrenal glucocorticoid and androgen responses to the $1 \mu \mathrm{g} \mathrm{ACTH} \mathrm{1-24} \mathrm{test} \mathrm{were} \mathrm{investigated} \mathrm{in}$ 23 premenopausal RA and in 15 age- and BMI-matched healthy females. Twelve RA patients were on low-dose prednisone $(<8.5 \mathrm{mg} /$ day $)$. Patients with DAS28 $>3.2$ had lower $(p<0.05)$ total plasma cortisol, 17-hydroxyprogesterone, dehydroepiandrosterone and androstenedione responses in the ACTH test compared to healthy controls. Patients with DAS28 $>3.2$ had lower $(p<0.05)$ dehydroepiandrosterone response in the ACTH test compared to patients with DAS28 $\leq 3.2$. C-reactive protein (CRP), DAS28, and interleukin (IL)-6 negatively correlated with androstenedione response to ACTH 1-24. Responses of all measured adrenal steroids were lower $(p<0.05)$ in patients on low-dose glucocorticoids compared to healthy controls. RA patients not treated with glucocorticoids had lower total cortisol response $(p=0.038)$ but did not differ in free plasma cortisol in the ACTH test. The results indicate an association of increased disease activity with a decrease in adrenal androgen production in RA and normal cortisol bioavailability in patients not treated with glucocorticoids.

\section{Key words}

Rheumatoid arthritis • Cortisol • Hypothalamic-pituitary-adrenal axis

\section{Corresponding author}

Richard Imrich, Center for Molecular Medicine, Institute of
Experimental Endocrinology, Slovak Academy of Sciences, Vlarska 3-7, 83101 Bratislava, Slovak Republic.

Fax: +421 25932 7725. E-mail: richard.imrich@savba.sk

\section{Introduction}

The hypothalamic-pituitary-adrenal (HPA) axis is an important immune modulator, primarily in view of potent anti-inflammatory effects of adrenal glucocorticoids. The inappropriately low HPA function has been suspected to be a permissive mechanism for excessive immune response leading to autoimmunity development. Rheumatoid arthritis (RA) has been considered a prototypical autoimmune disorder, in which HPA dysfunction contributes to its complex pathogenesis (Masi and Aldag 2005).

A complex of disease-related factors such as release of inflammatory mediators to systemic circulation and local nerve signaling from affected joints, results in specific neuroendocrine changes such as HPA hypofunction (Masi and Aldag 2005). Proinflammatory cytokines have been considered one of the main mediators of adrenal dysfunction in RA (Herrmann et al. 2002). Several studies analyzed correlation between disease activity and HPA function in RA; however only a few investigated adrenal androgen function (Boss and Neeck 2000, Eijsbouts et al. 2005, Straub et al. 2008). Recently, Straub and coworkers provided clinical evidence indicating interference of proinflammatory cytokines with adrenal androgen steroidogenesis (Straub 
et al. 2006). On the other hand, no evidence was found for immune and HPA axis activity markers as mediators of the stress-disease relationship (Evers et al. 2013).

Studies investigating adrenocortical dysfunction in RA have been mostly based on quantification of total serum (or plasma) cortisol investigating different aspects of the HPA axis including adrenocortical functional capacity, negative-feedback control of the HPA or cortisol kinetics. Approximately $90 \%$ of circulating cortisol is bound to cortisol-binding globulin and albumin. Only a small, unbound or "free" fraction of cortisol is, however, responsible for biological functions of the hormone. Given the fact that even subtle variations in factors regulating cortisol bioavailability can have a significant impact on cortisol actions in target tissues, a measuring of free serum cortisol characterizes adrenocortical function more accurately compared to total serum cortisol measurement (le Roux et al. 2002).

The first aim of our study was to investigate adrenocortical function in relation to disease and inflammatory activity in a group of premenopausal RA females by investigating responses of several adrenal steroids in the ACTH stimulation test. The second aim of our study was to analyze cortisol bioavailability in RA. Free cortisol quantification was performed by a recently developed equilibrium dialysis method (Kirchhoff et al. 2011). As far as we know, free cortisol has not been studied in RA yet. As recently reviewed by Chapman and coworkers, both beneficial and detrimental effects may result from $11 \beta$-hydroxysteroid dehydrogenase type 1 inhibition in chronic inflammatory disease (Chapman et al. 2013). In our study, activity of $11 \beta$-hydroxysteroid dehydrogenase type 1 activity was estimated at systemic level and in the subcutaneous adipose tissue, based on assumption that altered cortisone to cortisol conversion could also contribute to HPA axis hypofunction in RA (Chapman et al. 2009, Hillier 2007, Spies et al. 2009).

\section{Subjects and Methods}

\section{Patients and controls}

Twenty-three $(n=23)$ female patients fulfilling the 2010 ACR / EULAR classification criteria for RA were studied (Aletaha et al. 2010). The patients were recruited from the National Institute of Rheumatic Diseases in Piestany, Slovakia. Fifteen $(n=15)$ age- and body mass index-matched healthy female subjects served as controls. Characteristics of all subjects are shown in Table 1. All patients and controls had negative history of endocrine disorder, diabetes or impaired glucose tolerance and were non-smokers. None of the patients has been treated with anti-TNF, anti-IL-6 or any other biologics. The last dose of medicaments was administered to RA patients on the day before the testing. RA activity was quantified as disease activity score 28 (DAS28) with three variables i.e. number of swollen joints, number of tender joints and plasma C-reactive protein (CRP) concentration using an online calculator http://www.das-score.nl/dasculators.html. Eight $(\mathrm{N}=8)$ RA patients had low (DAS28-CRP $\leq 3.2)$, fourteen $(\mathrm{N}=14)$ patients had moderate (DAS28-CRP $>3.2$ and $\leq 5.1$ ), and one $(\mathrm{N}=1)$ patient had high $(\mathrm{DAS} 28-\mathrm{CRP}>5.1)$ disease activity. Patients with moderate and high disease activity were considered a single RA group (Table 1). Study was performed in accordance with the Declaration of Helsinki and was approved by the Ethics Committee of the National Institute of Rheumatic Diseases, Piestany, Slovakia. All subjects gave informed written consent.

\section{ACTH stimulation test}

Both patients and controls were investigated under the same conditions, after an overnight fast. An indwelling catheter was inserted into the cubital vein for blood sampling. To eliminate stress effect of a venepuncture, the blood sample for basal values was taken at least $30 \mathrm{~min}$ after inserting the catheter. After baseline sample was taken at about 10:00 AM, $1 \mu \mathrm{g}$ ACTH 1-24 in $1 \mathrm{ml}$ of sterile saline was administered as an intravenous bonus. The ACTH $1-24$ solution $(1 \mu \mathrm{g} / \mathrm{ml})$ was prepared immediately before the test by diluting ACTH 1-24 stock solution $(20 \mu \mathrm{g} / \mathrm{ml})$ in sterile saline. The ACTH 1-24 stock solution $(20 \mu \mathrm{g} / \mathrm{ml})$ was prepared from $250 \mu \mathrm{g} / \mathrm{ml}$ tetracosactrin (Synacthen $\AA$, Novartis Pharma AG, Basel, Switzerland) and was stored no more than one month at $4{ }^{\circ} \mathrm{C}$ in a sterile glass vial. At intervals shown in Fig. 1, blood samples were collected into polyethylene tubes containing EDTA as anticoagulant and immediately cooled.

\section{Cortisone acetate test}

A conversion of inactive cortisone to active cortisol at systemic level and in subcutaneous adipose tissue was investigated in six $(\mathrm{N}=6)$ glucocorticoid-naïve RA females and six $(\mathrm{N}=6)$ controls. All six RA patients were on methotrexate, non-steroid anti-inflammatory drugs and five patients were on disease activity modifying drugs. An average DAS28 of the six RA patients was 2.81 and average CRP was $2.12 \mu \mathrm{g} / \mathrm{ml}$ on 
the day of ACTH stimulation test. The cortisone acetate test was performed on a different day as the ACTH stimulation test. A total of $1.5 \mathrm{mg}$ of dexamethasone per os (Dexamethazon Léčiva, Zentiva a.s., Praha, Czech Republic) was used in two doses; $1 \mathrm{mg}$ at $11 \mathrm{PM}$ on a day before the test, and $0.5 \mathrm{mg}$ at 8:30 AM on the testing day, to suppress an endogenous cortisol production. After baseline blood samples were collected, $25 \mathrm{mg}$ of cortisone acetate per os (Cortison CIBA, Novartis Pharma GmbH, Nürnberg, Germany) was administered at about 9:30 AM. In addition to an i.v. catheter for blood sampling, a microdialysis probe with $20 \mathrm{kDa}$ cut-off membrane (CMA 60, CMA Microdialysis AB, Solna, Sweden) was inserted paraumbilically to the subcutaneous adipose tissue. The probe was perfused with Perfusion Fluid T1 at speed $0.5 \mu 1 / \mathrm{min}$ using CMA 107 Pump and microdialysate was collected to microvials in $1 \mathrm{~h}$ interval over $4 \mathrm{~h}$ (all CMA Microdialysis AB, Solna, Sweden).

Table 1. Basic characteristics, basal concentrations of cytokines, steroids and corticosteroid-binding globulin (CBG) and dehydroepiandrosterone sulfate (DHEAS) concentrations as well as adrenal steroid responses to $1 \mu \mathrm{g}$ ACTH 1-24 expressed as area under the response curve above baseline of 23 females with rheumatoid arthritis (RA) divided according to their disease activity score 28 (DAS28) and of 15 healthy females.

\section{RA RA RA Controls \\ $($ DAS28 $\leq$ 3.2) $\quad($ DAS28 $>3.2)$}

\begin{tabular}{|c|c|c|c|c|}
\hline Number & 23 & 8 & 15 & 15 \\
\hline Age (years) & $30.1 \pm 1.2$ & $29.6 \pm 2.4$ & $30.3 \pm 1.3$ & $29.9 \pm 1.3$ \\
\hline$B M I\left(k g / m^{2}\right)$ & $21.5 \pm 0.6$ & $21.6 \pm 1.0$ & $21.4 \pm 0.7$ & $21.6 \pm 0.5$ \\
\hline disease duration (years) & $7.4 \pm 0.7$ & $7.4 \pm 1.3$ & $7.4 \pm 0.9$ & - \\
\hline$D A S 28-C R P$ & $3.4 \pm 0.2$ & $2.2 \pm 0.3$ & $4.0 \pm 0.2$ & - \\
\hline Glucocorticoids & 12 & 4 & 8 & - \\
\hline NSAID & 22 & 7 & 15 & - \\
\hline Methotrexate & 19 & 6 & 13 & - \\
\hline Other DMARD & 13 & 5 & 8 & - \\
\hline$C R P(\mu g / m l)$ & $7.1 \pm 2.9^{* *}$ & $0.9 \pm 0.6$ & $11.3 \pm 4.4^{* \#}$ & $1.2 \pm 1.0$ \\
\hline$I L-1 \beta(p g / m l)$ & $0.7 \pm 0.4$ & $0.2 \pm 0.1$ & $1.0 \pm 0.6$ & $0.1 \pm 0.0$ \\
\hline$I L-4(\mathrm{pg} / \mathrm{ml})$ & $0.1 \pm 0.1$ & $0.0 \pm 0.0$ & $0.2 \pm 0.2$ & $0.0 \pm 0.0$ \\
\hline$I L-6(p g / m l)$ & $18.2 \pm 5.8^{* * *}$ & $5.2 \pm 2.8$ & $25.1 \pm 8.3 * * \#$ & $1.4 \pm 0.5$ \\
\hline$I L-8(\mathrm{pg} / \mathrm{ml})$ & $5.6 \pm 2.4^{* *}$ & $2.5 \pm 0.2$ & $7.2 \pm 3.6$ & $2.2 \pm 0.2$ \\
\hline$I L-10(\mathrm{pg} / \mathrm{ml})$ & $12.4 \pm 11.2$ & $0.9 \pm 0.7$ & $18.5 \pm 17.2$ & $0.7 \pm 0.4$ \\
\hline$I L-17(\mathrm{pg} / \mathrm{ml})$ & $17.4 \pm 17.3$ & $0.0 \pm 0.0$ & $26.6 \pm 26.5$ & $0.0 \pm 0.0$ \\
\hline$I F N \gamma(p g / m l)$ & $16.6 \pm 10.5$ & $1.8 \pm 1.5$ & $24.6 \pm 15.9$ & $2.1 \pm 1.4$ \\
\hline$T N F \alpha(p g / m l)$ & $13.4 \pm 10.9^{*}$ & $0.8 \pm 0.4$ & $20.1 \pm 16.7$ & $0.6 \pm 0.2$ \\
\hline$C B G(\mu g / m l)$ & $52.2 \pm 5.3$ & $41.1 \pm 2.2 * \#$ & $59.1 \pm 7.9$ & $55.3 \pm 5.3$ \\
\hline $\begin{array}{l}\text { Dehydroepiandrosterone } \\
\text { sulfate ( } \mu \mathrm{mol} / \mathrm{l})\end{array}$ & $3.3 \pm 0.5$ & $3.5 \pm 1.0$ & $3.2 \pm 0.6$ & $4.3 \pm 0.6$ \\
\hline Total cortisol ( $\mathrm{min}^{*}$ nmol/l) & $14242 \pm 1377 * *$ & $14841 \pm 1700^{*}$ & $13923 \pm 1944^{*}$ & $21608 \pm 2528$ \\
\hline $\begin{array}{l}\text { Free plasma cortisol } \\
\left(\mathrm{min}^{*} \text { nmol/l) }\right.\end{array}$ & $1618 \pm 150$ & $1669 \pm 273$ & $1590 \pm 185$ & $2067 \pm 215$ \\
\hline $\begin{array}{l}\text { 17-Hydroxyprogesterone } \\
\left(\min ^{*} \mathrm{nmol} / \mathrm{l}\right)\end{array}$ & $85 \pm 17$ & $126 \pm 35$ & $63.4 \pm 15^{*}$ & $127 \pm 23$ \\
\hline $\begin{array}{l}\text { Dehydroepiandrosterone } \\
\left(\mathrm{min}^{*} \text { nmol/l) }\right.\end{array}$ & $383 \pm 78 *$ & $593 \pm 169$ & $270 \pm 67 * * \#$ & $727 \pm 145$ \\
\hline $\begin{array}{l}\text { Androstenedione } \\
\left(\min ^{*} \text { nmol/l) }\right.\end{array}$ & $32 \pm 16$ & $53 \pm 40$ & $21 \pm 13^{* *}$ & $77 \pm 17$ \\
\hline
\end{tabular}

$* \mathrm{p}<0.05, * * \mathrm{p}<0.01, * * * \mathrm{p}<0.001$ RA vs. Controls; \# $\mathrm{p}<0.05$ RA (DAS28 $\leq 3.2)$ vs. RA (DAS28 $>3.2$ ) 

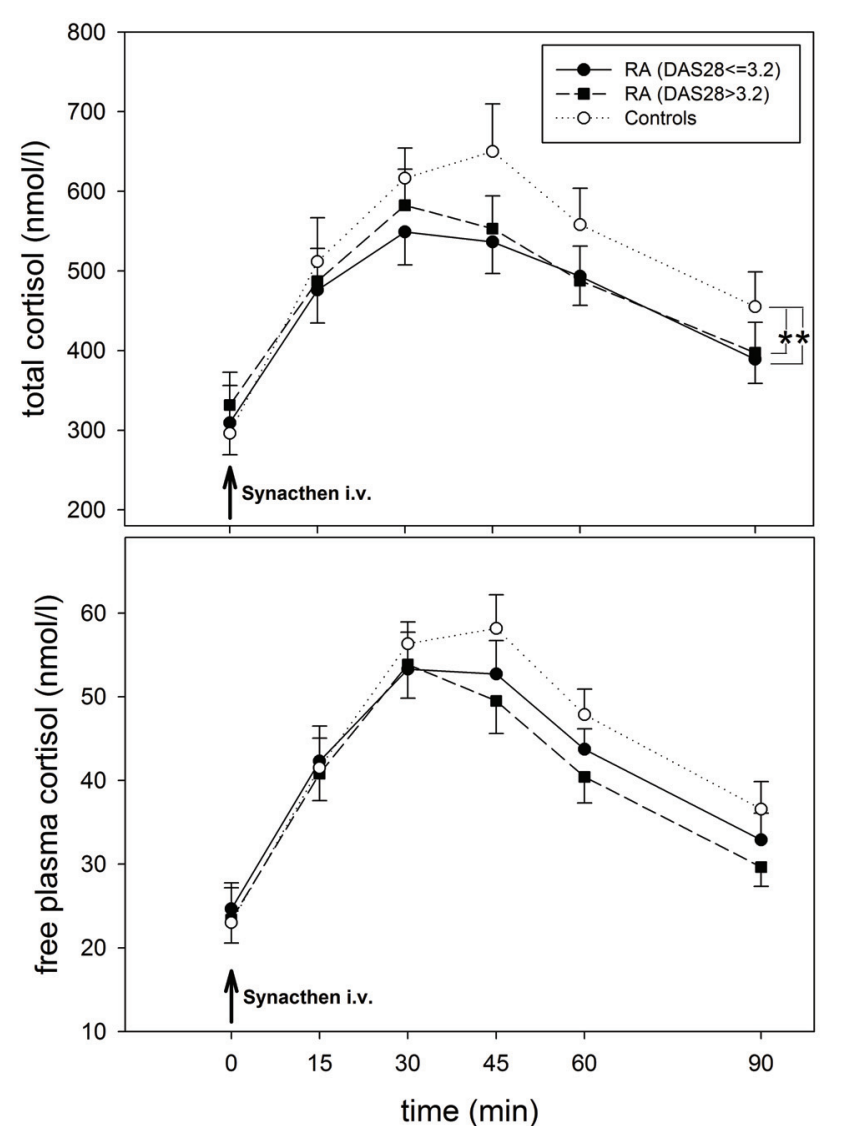

Fig. 1. Response of total plasma cortisol (top) and free plasma cortisol (bottom) to $1 \mu \mathrm{g} \mathrm{ACTH} 1-24$ (Synacthen $\AA$ ) in $8 \mathrm{RA}$ females with $C$-reactive protein-derived disease activity score (DAS28) $\leq 3.2$ (black circles), 15 RA patients with DAS28 $>3.2$ (black squares) and in 15 healthy controls (white circles). Asterisks indicate the following difference in area under the response curve above baseline: RA vs. Controls $* p<0.05$.

\section{Assays and statistics}

After centrifugation of plasma aliquots, all samples including the microdialysate were stored at $-20^{\circ} \mathrm{C}$ until analyzed. Corticosteroid-binding globulin (CBG) concentrations in plasma were measured by radioimmunometric assay (Asbach Medical Products GmBH, Obrigheim, Germany). Total plasma cortisol, 17hydroxyprogesterone (17OHP), androstenedione (ASD), dehydroepiandrosterone (DHEA) and dehydroepiandrosterone sulfate (DHEAS) was measured by immunoradiometric assay (Immunotech S.A., Beckman Coulter Group, Marseille, France). Concentrations of free plasma cortisol were determined by equilibrium dialysis method with subsequent measurement using liquid chromatography electrospray tandem mass spectrometry (LC-ESI/MS/MS) (Kirchhoff et al. 2011, Vogeser et al. 2002). Cortisol in microdialysis samples was measured by Salivary Cortisol ELISA kit (IBL GmbH, Hamburg, Germany). Plasma interleukin (IL)-1 $\beta$, IL-4, IL-6, IL-8,
IL-10, IL-17, interferon gamma (IFN $\gamma$ ) and tumor necrosis factor alpha (TNF $\alpha$ ) concentrations were assayed using bead-based immunoassay kit (Bio-Plex, Bio-Rad Laboratories, Hercules, CA, USA). CRP concentrations were assayed by an immunoturbidimetric assay.

Stimulated responses of adrenal hormones were quantified as area under the response curve above baseline of each hormone. The area was calculated after subtraction of basal value (time $0 \mathrm{~min}$ ) from the concentrations in 15-90 min of the ACTH stimulation test using trapezoidal rule. General linear model for repeated measures (GLM-RM) procedure was used to determine the differences in hormone responses in the ACTH stimulation test between patients and controls. Comparisons of basal hormone and cytokine concentrations were evaluated by unpaired t-test or nonparametric test for independent samples. Statistical evaluation was performed using IBM SPSS Statistics v.19 (SPSS Inc., and IBM Company, USA) software. All data are expressed as mean \pm standard error mean. Significance was set at $\mathrm{p}<0.05$.

\section{Results}

\section{Disease activity, inflammation and adrenal function}

RA patients with moderate to high disease activity had higher plasma CRP and IL-6 concentrations compared to controls or patients with low disease activity. RA patients had higher TNF $\alpha$ compared to controls $(p<0.05)$.

The mean basal concentrations of $\mathrm{CBG}$ in plasma was lower in RA patients with low disease activity compared to patients with moderate to high activity or healthy controls $(\mathrm{p}<0.05)$ (Table 1$)$. The mean basal concentrations of total plasma cortisol, free plasma cortisol, 17OHP and DHEA, DHEAS were comparable between RA patients and healthy controls. The mean basal concentrations of plasma ASD were lower in patients with moderate to high disease activity compared to patients with low disease activity or healthy controls $(\mathrm{p}<0.05)$.

Total plasma cortisol, free plasma cortisol, 17OHP, ASD and DHEA concentrations significantly $(p<0.001)$ increased during the ACTH stimulation test (Fig. 1, Fig. 2). As shown by area under the response curve above baseline, total cortisol responses were lower in both RA subgroups compared to controls $(\mathrm{p}<0.05)$, however free plasma cortisol did not differ between RA patients and controls (Fig. 1, Table 1). 17OHP responses 
tended to be lower in patients with moderate to high disease activity compared to RA patients with low diseases $(p=0.071)$ activity and controls $(p=0.03)$. DHEA responses in the ACTH stimulation test were significantly lower in patients with moderate to high disease activity compared to RA patients with low disease activity $(p=0.008)$ or healthy controls $(p=0.046)$ (Fig. 2, Table 1). Responses of ASD were lower in RA patients with moderate to high disease activity compared to controls $(p=0.008)$. The trend to lower stimulated adrenal androgen response in RA patients with moderate to high disease activity was also confirmed by GLM-RM procedure showing time $\times$ disease interactions for ASD $(p=0.064)$ and DHEA $(p=0.068)$, when compared with healthy controls.

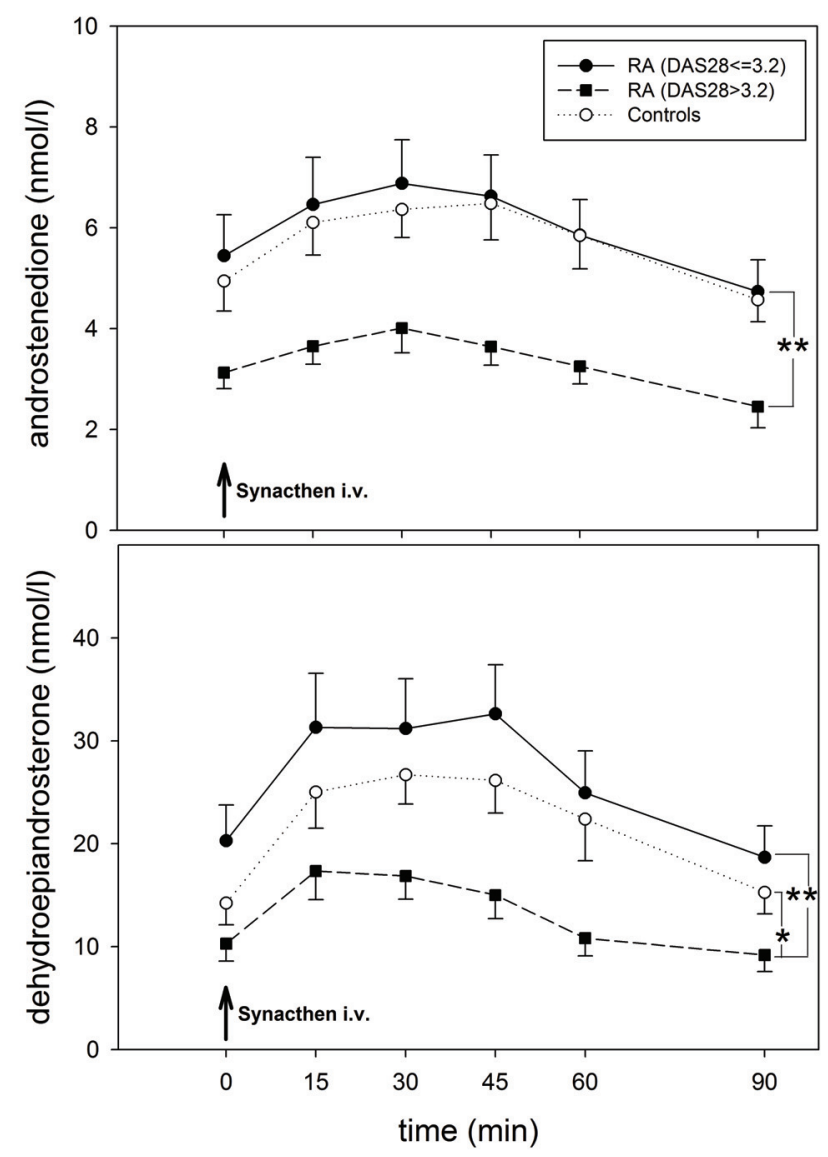

Fig. 2. Response of androstenedione (top) and dehydroepiandrosterone (bottom) to $1 \mu \mathrm{g} \mathrm{ACTH} \mathrm{1-24} \mathrm{(Synacthen} ®$ ) in 8 RA females with C-reactive protein-derived disease activity score (DAS28) $\leq 3.2$ (black circles), 15 RA patients with DAS28>3.2 (black squares) and in 15 healthy controls (white circles). Asterisks indicate the following difference in area under the response curve above baseline: RA (DAS28>3.2) vs. Controls $* \mathrm{p}<0.05$, RA (DAS28 $\leq 3.2)$ vs. RA (DAS28 $>3.2) * * \mathrm{p}<0.01$.
Baseline concentrations of cytokines and CRP are shown in Table 1. As expected RA patients had higher CRP, IL-6, IL-8 and TNF $\alpha$ levels compared to controls. Patients with high disease activity had higher CRP and IL-6 compared to controls and compared to RA patients with low disease activity. As expected, DAS28 positively correlated with CRP $(r=0.65, p=0.001)$. DAS28 positively correlated with the following cytokines IL-6 $(\mathrm{r}=0.69, \mathrm{p}<0.001)$, IL-8 $(\mathrm{r}=0.64, \mathrm{p}=0.001)$ and IFN $\gamma$ $(\mathrm{r}=0.53, \mathrm{p}=0.003)$. DAS28 negatively correlated with responses of DHEA and ASD, but not with responses of glucocorticoids (Table 2). Correlations between stimulated adrenal steroids responses and inflammatory markers are summarized in Table 2. Among all cytokines measured in our study, IL-6 and IL-8 negatively correlated with adrenal androgen responses, whereas glucocorticoid responses negatively correlated with IL-8, IL-17 (Table 2). Number of tender joints positively correlated with IL-1 $\beta \quad(\mathrm{r}=0.49, \mathrm{p}=0.03)$, IL-6 $(\mathrm{r}=0.71$, $\mathrm{p}<0.001), \quad$ IL-8 $\quad(\mathrm{r}=0.57, \quad \mathrm{p}=0.008), \quad$ IFN $\gamma \quad(\mathrm{r}=0.89$, $\mathrm{p}<0.001), \mathrm{TNF} \alpha(\mathrm{r}=0.45, \mathrm{p}=0.05)$ and negatively with ASD response $(r=-0.64, p=0.002)$.

\section{Low-dose glucocorticoids and adrenal function}

Assuming a suppressive effect of glucocorticoid treatment on inflammation and adrenal function, we analyzed cytokines and responses of adrenal steroids in the ACTH stimulation test according to presence or absence of low-dose glucocorticoid treatment. Patients on the glucocorticoids had higher IL-6 $(p=0.05)$ compared to glucocorticoid-untreated RA patients.

There were no significant differences in baseline concentrations of $\mathrm{CBG}$, total cortisol, free plasma cortisol, 17OHP, ASD, DHEA and DHEAS between RA patients on low-dose glucocorticoids and without glucocorticoids. Responses of these steroids did not differ between glucocorticoid-treated and glucocorticoiduntreated RA patients. As expected, patients on low-dose glucocorticoids had significantly $(\mathrm{p}<0.05) \quad$ lower responses of total plasma cortisol, free plasma cortisol, ASD, DHEA compared to controls. RA patients not treated with glucocorticoids had lower total cortisol response $(p=0.038)$ compared to controls, however the RA groups did not differ in other steroids measured in our study including free plasma cortisol.

\section{$11 \beta$ HSD activity}

A suppression of endogenous cortisol production was achieved in all 12 studied subjects before the 
cortisone acetate test with cortisol levels in plasma and microdialysate at the low limit for detection. Administration of cortisone was followed by a significant $(\mathrm{p}<0.001)$ increase in total plasma cortisol, free plasma cortisol and adipose tissue cortisol with a peak at about $180 \mathrm{~min}$. There was no significant difference between RA patients and controls in cortisone to cortisol conversion during the test (Fig. 3).

Table 2. Column 1 shows non-parametric Spearman coefficients $r$ for correlations between C-reactive protein-derived disease activity score (DAS28) and adrenal steroid responses to $1 \mu \mathrm{g}$ ACTH 1-24 in 23 patients with rheumatoid arthritis (RA). Columns 2 to 5 show Spearman coefficients $r$ for correlations between inflammatory markers and stimulated adrenal steroid responses in 23 RA patients and 15 healthy controls. Adrenal steroid responses are expressed as area under the response curve above baseline.

\begin{tabular}{|c|c|c|c|c|c|}
\hline & $\begin{array}{c}\text { DAS28 } \\
n=23\end{array}$ & $\begin{array}{l}\text { CRP } \\
n=38\end{array}$ & $\begin{array}{l}\text { IL-6 } \\
n=38\end{array}$ & $\begin{array}{l}\text { IL-8 } \\
\text { n=38 }\end{array}$ & $\begin{array}{c}\text { IL-17 } \\
\mathbf{n}=\mathbf{3 8}\end{array}$ \\
\hline Total cortisol $\left(\mathrm{min}^{*} \mathrm{nmol} / \mathrm{l}\right)$ & 0.13 & -0.28 & -0.19 & $-0.34 *$ & $-0.33^{*}$ \\
\hline Free plasma cortisol (min*nmol/l) & 0.03 & -0.28 & -0.25 & $-0.43 * *$ & $-0.34^{*}$ \\
\hline 17-Hydroxyprogesterone ( $\mathrm{min}^{*}$ nmol/l) & -0.07 & -0.18 & -0.19 & -0.31 & $-0.35^{*}$ \\
\hline Dehydroepiandrosterone ( $\mathrm{min}^{*}$ nmol/l) & $-0.34^{*}$ & $-0.50 * * *$ & $-0.39 *$ & $-0.46^{* *}$ & -0.08 \\
\hline Androstenedione $(\min * n m o l / l)$ & $-0.55^{* *}$ & $-0.40 *$ & $-0.51 * * *$ & $-0.47 * *$ & -0.01 \\
\hline
\end{tabular}

$* \mathrm{p}<0.05, * * \mathrm{p}<0.01, * * * \mathrm{p}<0.001$
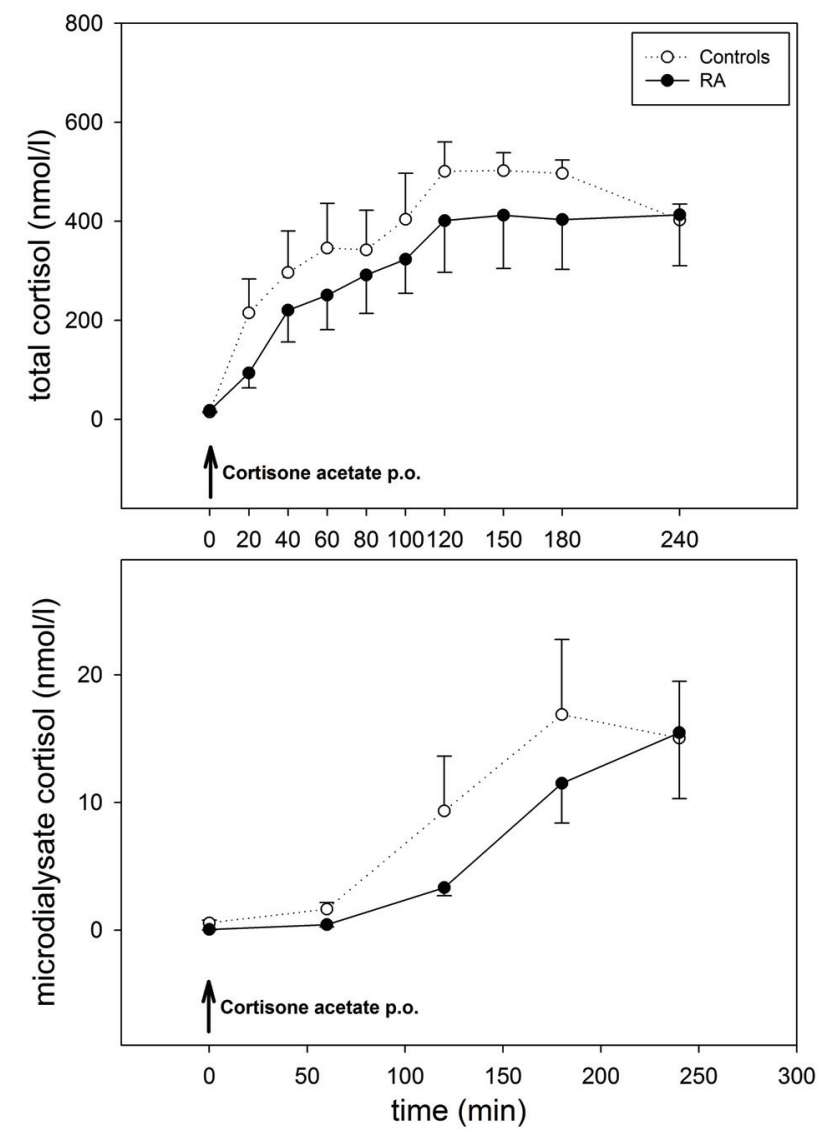

Fig. 3. Cortisone to cortisol conversion at systemic level (top) and in subcutaneous adipose tissue (bottom) in six $(\mathrm{N}=6)$ glucocorticoid-naïve RA females (black circles), and six $(\mathrm{N}=6)$ controls (white circles) after endogenous cortisol production suppression by $1.5 \mathrm{mg}$ of dexamethasone per os.

\section{Discussion}

In the present study, we analyzed a relationship between adrenocortical function and disease-related factors in premenopausal females with RA. The novel findings our study provides is that RA patients with moderate to high disease activity had decreased production of adrenal androgens in the ACTH stimulation test while decrease in cortisol response was found to be independent of disease activity. Our findings support the view of androgen-producing zona reticularis function is affected more by the ongoing inflammatory disease than glucocorticoid-producing zona fasciculate shifting steroidogenesis from adrenal androgens to glucocorticoids (Straub et al. 2002a,b, Zietz et al. 2000). The similar findings were reported in patients with polymyalgia (Cutolo et al. 2002). The observed lower cortisol response in the ACTH stimulation test very likely reflects low-dose glucocorticoid treatment in about half of the patients in low and moderate to high disease activity subgroups.

When we analyzed a relation of DAS28 components on adrenal function, CRP levels and number of tender joints was negatively related to stimulated adrenal androgen production in our RA patients. In addition to CRP-derived DAS28, a panel of 8 inflammatory cytokines was correlated with parameters of adrenal steroid function. We found that IL-6 negatively correlated with adrenal androgen production but not with 
glucocorticoids. IL-6 has been considered one of the main systemic mediators of chronic inflammation in humans (Tsigos et al. 1997). Our findings support the hypothesis that IL-6 and possibly other cytokines such as IL-8 and IL-17 are responsible for observed shift in steroidogenesis from adrenal androgens to glucocorticoids in RA suggesting that adrenal androgen hypofunction is a result of inflammatory process (Straub et al. 2006, Zietz et al. 2000). A detailed investigation of adrenal function in patients on anti-IL-6 treatment would provide important evidence for the suggested close interplay between inflammatory mediators and the adrenals. On the other, our data does not provide support for inherent lower HPA activity as a predisposing factor for RA development (Masi and Aldag 2005). This is in line with a recent study showing that steroid hormone levels measured at a single time point prior to RA onset were not associated with RA risk (Karlson et al. 2009). Interestingly, our study did not show a significant relationship between TNF-alpha and adrenal function as shown by others (Straub et al. 2008).

In the present study, we also analyzed adrenal function in our RA patients according to glucocorticoid treatment status. As expected, our results clearly demonstrate that treatment with less than $8.5 \mathrm{mg}$ of prednisone equivalent daily resulted in a significant suppression of adrenocortical reserve. This confirms a previous study showing that low-dose glucocorticoid treatment can have a significant effect on adrenal function (Kirwan et al. 2006). Thus, the fact that about half of our RA patients were on low-dose glucocorticoids can be a limitation of our study. However, a balanced distribution of RA patients on glucocorticoids between patients with low and moderate to high disease activity allowed us to control for this factor.

We also observed a minor decrease in total cortisol response in glucocorticoid untreated patients. However, this small decrease did not affect free plasma cortisol, a measure of cortisol bioavailability. Alterations of cortisol responses in the ACTH stimulation test observed in our study are in line with a study, in which insulin-induced hypoglycemia resulted in a minor tendency to lower interval-specific cortisol response in RA patients (Gutierrez et al. 1999). Another study showed similar ACTH but lower cortisol responses to hypoglycemia in RA patients compared to controls (Eijsbouts et al. 2005). Other studies did not find any significant differences in total cortisol response to a synthetic ACTH analogue or corticotropin releasing hormone (Cutolo et al. 1999, Hasan et al. 2009, Templ et al. 1996). The variability of the results demonstrates that HPA activity depends on many factors including actual disease activity.

The regulated variable in the control circuit of adrenal function is free bioavailable cortisol. The adrenal cortex adjusts cortisol synthesis to maintain adequate free serum cortisol. Our findings of comparable free cortisol response but lower total cortisol response to ACTH in RA can be viewed as a non-adrenal compensatory mechanism for the subtle decrease in adrenal production of cortisol in RA. Moreover, our results showed unaltered cortisone to cortisol conversion in our RA patients suggesting that $11 \beta$ HSD type 1 enzyme activity might not be responsible for the observed subtle decrease in total cortisol production. These results have to be confirmed on a larger group of RA patients since only a small number of our RA subjects underwent the cortisone acetate test.

In conclusion, the present data indicate an association of increased disease activity with a decrease in adrenal androgen production in RA. Humoral factors including IL-6 are very likely the mediators of the observed adrenal androgen suppression. A modest suppression of stimulated cortisol in glucocorticoiduntreated RA patients is not associated with decreased cortisol bioavailability. Our data provide a clinical evidence for a specific suppressive effect of inflammation on adrenal androgen function in RA.

\section{Conflict of Interest}

There is no conflict of interest.

\section{Acknowledgements}

Authors appreciate Mrs. Emilia Andelova for her skillful technical assistance. This work was supported by the grants MVTS, VEGA 2/0187/09, FM/EEA SK0095 and N00024 RASGENAS. 


\section{References}

ALETAHA D, NEOGI T, SILMAN AJ, FUNOVITS J, FELSON DT, BINGHAM CO, BIRNBAUM NS, BURMESTER GR, BYKERK VP, COHEN MD, COMBE B, COSTENBADER KH, DOUGADOS M, EMERY P, FERRACCIOLI G, HAZES JM, HOBBS K, HUIZINGA TW, KAVANAUGH A, KAY J, KVIEN TK, LAING T, MEASE P, MENARD HA, MORELAND LW, NADEN RL, PINCUS T, SMOLEN JS, STANISLAWSKA-BIERNAT E, SYMMONS D, TAK PP, UPCHURCH KS, VENCOVSKY J, WOLFE F, HAWKER G: 2010 rheumatoid arthritis classification criteria: an American College of Rheumatology/European League Against Rheumatism collaborative initiative. Ann Rheum Dis 69: 1580-1588, 2010.

BOSS B, NEECK G: Correlation of IL-6 with the classical humoral disease activity parameters ESR and CRP and with serum cortisol, reflecting the activity of the HPA axis in active rheumatoid arthritis. Z Rheumatol $\mathbf{5 9}$ (Suppl 2): II/62-64, 2000.

CHAPMAN KE, COUTINHO AE, GRAY M, GILMOUR JS, SAVILL JS, SECKL JR: The role and regulation of 11beta-hydroxysteroid dehydrogenase type 1 in the inflammatory response. Mol Cell Endocrinol 301: 123-131, 2009.

CHAPMAN KE, COUTINHO AE, ZHANG Z, KIPARI T, SAVILL JS, SECKL JR: Changing glucocorticoid action: $11 \beta$-Hydroxysteroid dehydrogenase type 1 in acute and chronic inflammation. $J$ Steroid Biochem Mol Biol 137: 82-92, 2013.

CUTOLO M, FOPPIANI L, PRETE C, BALLARINO P, SULLI A, VILLAGGIO B, SERIOLO B, GIUSTI M, ACCARDO S: Hypothalamic-pituitary-adrenocortical axis function in premenopausal women with rheumatoid arthritis not treated with glucocorticoids. J Rheumatol 26: 282-288, 1999.

CUTOLO M, STRAUB RH, FOPPIANI L, PRETE C, PULSATELLI L, SULLI A, BOIARDI L, MACCHIONI P, GIUSTI M, PIZZORNI C, SERIOLO B, SALVARANI C: Adrenal gland hypofunction in active polymyalgia rheumatica: effect of glucocorticoid treatment on adrenal hormones and interleukin 6. J Rheumatol 29: 748$756,2002$.

EIJSBOUTS AM, VAN DEN HOOGEN FH, LAAN RF, HERMUS AR, SWEEP CG, VAN DE PUTTE LB: Hypothalamic-pituitary-adrenal axis activity in patients with rheumatoid arthritis. Clin Exp Rheumatol 23: 658664, 2005.

EVERS AW, VERHOEVEN EW, VAN MIDDENDORP H, SWEEP FC, KRAAIMAAT FW, DONDERS AR, EIJSBOUTS AE, VAN LAARHOVEN AI, DE BROUWER SJ, WIRKEN L, RADSTAKE TR, VAN RIEL PL: Does stress affect the joints? Daily stressors, stress vulnerability, immune and HPA axis activity, and shortterm disease and symptom fluctuations in rheumatoid arthritis. Ann Rheum Dis 2013 (in press).

GUTIERREZ MA, GARCIA ME, RODRIGUEZ JA, MARDONEZ G, JACOBELLI S, RIVERO S: Hypothalamicpituitary-adrenal axis function in patients with active rheumatoid arthritis: a controlled study using insulin hypoglycemia stress test and prolactin stimulation. J Rheumatol 26: 277-281, 1999.

HASAN EA, JESSOP DS, POWER LL, MONK PT, KIRWAN JR: Use of the dexamethasone-corticotrophin releasing hormone test to assess hypothalamic-pituitary-adrenal axis function in rheumatoid arthritis. Int $J$ Endocrinol 2009: 1-6, 2009.

HERRMANN M, SCHOLMERICH J, STRAUB RH: Influence of cytokines and growth factors on distinct steroidogenic enzymes in vitro: a short tabular data collection. Ann N Y Acad Sci 966: 166-186, 2002.

HILLIER SG: Diamonds are forever: the cortisone legacy. J Endocrinol 195: 1-6, 2007.

KARLSON EW, CHIBNIK LB, MCGRATH M, CHANG SC, KEENAN BT, COSTENBADER KH, FRASER PA, TWOROGER S, HANKINSON SE, LEE IM, BURING J, DE VIVO I: A prospective study of androgen levels, hormone-related genes and risk of rheumatoid arthritis. Arthritis Res Ther 11: R97, 2009.

KIRCHHOFF F, BRIEGEL J, VOGESER M: Quantification of free serum cortisol based on equilibrium dialysis and isotope dilution-liquid chromatography-tandem mass spectrometry. Clin Biochem 44: 894-899, 2011.

KIRWAN JR, HICKEY SH, HALLGREN R, MIELANTS H, BJORCK E, PERSSON T, WOLLHEIM FA: The effect of therapeutic glucocorticoids on the adrenal response in a randomized controlled trial in patients with rheumatoid arthritis. Arthritis Rheum 54: 1415-1421, 2006. 
LE ROUX CW, SIVAKUMARAN S, ALAGHBAND-ZADEH J, DHILLO W, KONG WM, WHEELER MJ: Free cortisol index as a surrogate marker for serum free cortisol. Ann Clin Biochem 39: 406-408, 2002.

MASI AT, ALDAG JC: Integrated neuroendocrine immune risk factors in relation to rheumatoid arthritis: should rheumatologists now adopt a model of a multiyear, presymptomatic phase? Scand J Rheumatol 34: 342-352, 2005.

SPIES CM, BURMESTER GR, BUTTGEREIT F: Analyses of similarities and differences in glucocorticoid therapy between rheumatoid arthritis and ankylosing spondylitis - a systematic comparison. Clin Exp Rheumatol 27: S152-S158, 2009.

STRAUB RH, LEHLE K, HERFARTH H, WEBER M, FALK W, PREUNER J, SCHOLMERICH J: Dehydroepiandrosterone in relation to other adrenal hormones during an acute inflammatory stressful disease state compared with chronic inflammatory disease: role of interleukin-6 and tumour necrosis factor. Eur $J$ Endocrinol 146: 365-374, 2002a.

STRAUB RH, PAIMELA L, PELTOMAA R, SCHOLMERICH J, LEIRISALO-REPO M: Inadequately low serum levels of steroid hormones in relation to interleukin-6 and tumor necrosis factor in untreated patients with early rheumatoid arthritis and reactive arthritis. Arthritis Rheum 46: 654-662, 2002b.

STRAUB RH, HARLE P, YAMANA S, MATSUDA T, TAKASUGI K, KISHIMOTO T, NISHIMOTO N: Antiinterleukin-6 receptor antibody therapy favors adrenal androgen secretion in patients with rheumatoid arthritis: a randomized, double-blind, placebo-controlled study. Arthritis Rheum 54: 1778-1785, 2006.

STRAUB RH, PONGRATZ G, CUTOLO M, WIJBRANDTS CA, BAETEN D, FLECK M, ATZENI F, GRUNKE M, KALDEN JR, SCHOLMERICH J, LORENZ HM, TAK PP, SARZI-PUTTINI P: Increased cortisol relative to adrenocorticotropic hormone predicts improvement during anti-tumor necrosis factor therapy in rheumatoid arthritis. Arthritis Rheum 58: 976-984, 2008.

TEMPL E, KOELLER M, RIEDL M, WAGNER O, GRANINGER W, LUGER A: Anterior pituitary function in patients with newly diagnosed rheumatoid arthritis. Br J Rheumatol 35: 350-356, 1996.

TSIGOS C, PAPANICOLAOU DA, DEFENSOR R, MITSIADIS CS, KYROU I, CHROUSOS GP: Dose effects of recombinant human interleukin-6 on pituitary hormone secretion and energy expenditure. Neuroendocrinology 66: 54-62, 1997.

VOGESER M, BRIEGEL J, ZACHOVAL R: Dialyzable free cortisol after stimulation with Synacthen. Clin Biochem 35: 539-543, 2002.

ZIETZ B, REBER T, OERTEL M, GLUCK T, SCHOLMERICH J, STRAUB RH: Altered function of the hypothalamic stress axes in patients with moderately active systemic lupus erythematosus. II. Dissociation between androstenedione, cortisol, or dehydroepiandrosterone and interleukin 6 or tumor necrosis factor. J Rheumatol 27: 911-918, 2000. 